\title{
Kant, Frege, and the Normativity of LOGIC: MACFARLANE'S ARgUMENT FOR Common Ground
}

\author{
Topic Areas: Kant, Philosophy of Logic, Normativity, \\ Normativity of logic, Canon, Propaedeutic, Logicism, Frege
}

\begin{abstract}
According to what used to be the standard view (Poincaré, Wang, etc.), although Frege endorses, and Kant denies, the claim that arithmetic is reducible to logic, there is not a substantive disagreement between them because their conceptions of logic are too different. In his "Frege, Kant, and the logic in logicism," John MacFarlane aims to establish that Frege and Kant do share enough of a conception of logic for this to be a substantive, judicable dispute. MacFarlane maintains that for both Frege and Kant, the fundamental defining characteristic of logic is "that it provides norms for thought as such" [MacFarlane, 2002, p. 57]. I defend the standard view. I show that MacFarlane's argument rests on conflating the way that pure general logic is normative as a canon and as a propaedeutic, and that once these are distinguished the argument is blocked.
\end{abstract}




\section{Kant, Frege, And the Normativity of LOGIC: MaCFARlane's Argument FOR COMMON Ground}

\section{Introduction}

Frege attempted to reduce arithmetic to logic. Kant, however, held such a reduction was impossible, because he thought arithmetic required intuition. ${ }^{1}$ So there is an apparent dispute over whether arithmetic is reducible to logic-over logicism. Still, one might wonder whether this apparent dispute is substantive, because Kant and Frege have quite different conceptions of logic. Unless there is a common agreed on conception, it might turn out both that arithmetic is reducible to Frege's logic, while it is not reducible to Kant's.

Poincaré and Hao Wang think that this is how things go. According to Wang:

Frege thought that his reduction refuted Kant's contention that arithmetic truths are synthetic. The reduction, however, cuts both ways. [...] if [Frege's] reduction is really successful, one who believes firmly in the synthetic character of arithmetic can conclude that Frege's logic is thus proved to be synthetic rather than that arithmetic is proved to be analytic. [...] In the same vein, if one believes firmly in the irreducibility of arithmetic to logic, he will conclude from Frege's or Dedekind's successful reduction that what they take to be logic contains a good deal that lies outside the domain of logic. $^{2}$

Thus, Wang holds there is a standoff. Frege thinks he has refuted Kant and shown arithmetic to be an analytic matter of logic, but Kant is free to conclude that Frege's logic includes synthetic elements, and is not properly logic - or not properly logic in the relevant sense.

\footnotetext{
${ }^{1}$ (B16). A note about my abbreviations of Kant's works can be found at the end of the essay.

${ }^{2}$ [Wang, 1963, p. 80]; see also [Poincaré, 1914, p. 162].
} 
John MacFarlane, in his "Frege, Kant, and the logic in logicism," attempts to overcome this standoff and show that Frege and Kant do share enough of a conception of logic for them to have a substantive, judicable dispute over logicism. MacFarlane argues that for both Frege and Kant, the fundamental defining characteristic of logic is "that it provides norms for thought as such," and that because they share this conception, "Frege can argue that his Begriffsschrift is a logic in Kant's own sense," 4 even though these logics differ in other, less fundamental respects, such as whether they abstract away from the relation of representations to objects. ${ }^{5}$

Since its publication, MacFarlane's essay has become the go-to essay both on the general relationship between Kant's and Frege's conceptions of logic and on their specific dispute over logicism. ${ }^{6}$ This is in part because MacFarlane's essay significantly develops lines of thought introduced in prior discussions of the relationship between Kant's and Frege's conceptions of logic. ${ }^{7}$ And it is also surely because MacFarlane's essay is the driving force behind what Clinton Tol-

\footnotetext{
${ }^{3}$ [MacFarlane, 2002, p. 57]

4 [MacFarlane, 2002, p. 32]

${ }^{5}$ MacFarlane designates as "Formal" any logic that abstracts away from the relation representations stand in to their objects, as Kant would put it (A55/B79), or "that is completely indifferent to the semantic contents of concepts and judgments," as MacFarlane would put it [MacFarlane, 2002, p. 28]. He argues that Frege's logic is not 'Formal,' while Kant's is 'Formal.' I am not, myself, convinced that this is what either Kant or Frege mean when they discuss whether logic is formal. For this reason, I prefer to write out that they disagree over whether logic abstracts away from the relations representations stand in to objects. Because my focus here is on MacFarlane's claim that Kant and Frege share the same fundamental conception of logic, not on the ways in which their conceptions of logic differ, my unease about MacFarlane's 'Formality' is peripheral to my argument. For more on how I think MacFarlane's Formality relates to some other dimensions of the formality of Kant's pure general logic, see my [2020, $\S 3]$. And in my [2019] and [MS] I discuss two other dimensions of the formality of Kant's logic. The nature of formality in logic is an issue I intend to examine further in future work.

${ }^{6}$ E.g. Béatrice Longuenesse [2005, p. 89, n14], Michael Beaney [2006, p. 52, n4], Florian Steinberger [2017], and Thomas Hofweber [2017].

${ }^{7}$ I have in mind lines of thought introduced by Hans Sluga [1980], Alberto Coffa [1991], and Michael Wolff [1995]. Since MacFarlane's essay, a few examples of work that discuss this relationship from a Fregean direction are Øystein Linnebo [2003], Michael Kremer [2006], and Mark Textor [2010b, ch. 1]. Penelope Maddy [2007, esp.ch. III.2] has discussed their relation with an eye towards more contemporary concerns. Michael Wolff [2007] examines the relationship between Kant and Frege from a Kantian direction. Finally, in the late stages of preparing this essay, further substantial discussions of the relation between Kant's and Frege's conceptions of logic appeared by James Conant [2020] and Sanford Shieh [2019, ch. 1].
} 
ley describes as the "growing consensus that Kant and Frege ultimately agree on the nature of the generality of logic," where, "whatever else they might disagree about, Kant and Frege agree that logic's laws and forms are constitutive of all thought and reasoning as such, no matter what its object." 8 Despite its influence, and the bevy of scholars who seem to agree with the core of MacFarlane's interpretations, MacFarlane's argument itself has not received very much attention. ${ }^{9}$ In this essay I examine it, and argue we should not reject Wang's position on its basis, because it trades on an equivocation between different kinds of normativity.

MacFarlane's argument has two parts. First, he aims to establish that Kant and Frege share the same fundamental normative conception of logic. Second, he argues that, on Kant's view, it is not part of logic's nature that it abstracts away from objects, but that this only follows from Kant's extra-logical commitments. The second part builds on the conception of normativity developed in the first, and my focus will be on showing this first part does not hold up. Specifically, I argue that there are two different ways that the laws of Kant's pure general logic

\footnotetext{
${ }^{8}$ [Tolley, 2013, p. 431-432]. Recently, however, both myself [2019] and James Conant [2020] have suggested that Kant and Frege thought the laws of logic are constitutive for thinking in fundamentally different ways. And, as Tolley is, of course, well aware, within this 'consensus' there are substantive disputes. Most notably, neither Kant nor Frege scholars are in agreement on how exactly logic's laws are constitutive of all thought. With respect to Kant, some interpreters - e.g., Huaping Lu-Adler [2016] and Jessica Leech [2017]—agree with MacFarlane that the laws of logic are constitutive norms for how we ought to think. Others-e.g., James Conant [1992], Clinton Tolley [2006] and Melissa Merritt [2015]—hold logic's laws are constitutive criteria for being a thought, the violation of which makes a putative thought not a thought. While a third group-Matthew Boyle [2020], myself [2019], and James Conant [2020] - have tried to steer a middle course between the first two.

With respect to Frege, the current dominant reading is likely in line with MacFarlane'sother sophisticated normativist readings include those of William Taschek [2008] and Mark Textor [2010b]. Still, older readings like that of Thomas Ricketts [1985] and Warren Goldfarb [2001], stress that for Frege there is no meta-logical perspective. On these latter readings, we are to recognize Frege's logical axioms as logical in a piecemeal fashion (perhaps with the help of his elucidatory remarks), and there is no general criterion (such as normativity for thought as such) that can be applied (say, in a judgment) to decide whether or not a given candidate is a logical law or not. For a nice recent discussion of these issues, see [Shieh, 2019, ch. 5]. Although I am not going to be taking a stand in either of these interpretive discussions here, my views on Kant can be found in my "Logical Mistakes, Logical Aliens, and the Laws of Kants Pure General Logic" [2019].

${ }^{9}$ An exception is Tolley [2012]. I discuss his response further below (around note 69).
} 
are normative: as a canon, for coherently exercising the faculty for thinking, and as a propaedeutic, for forming true thoughts about objects. MacFarlane conflates these and assimilates the resulting normativity with the normativity he finds for Frege's logic. Once we distinguish the two kinds of normativity of pure general logic, however, MacFarlane will face a dilemma. If he holds it is their normativity for the faculty of thinking that is definitive of logical laws, then logic's abstraction away from objects will be an essential feature of it. If it is their normativity for truth that is definitive, this will be insufficient for showing a law is analytic. ${ }^{10}$ This is because normativity for truth is insufficient for deciding whether the law belongs to Kant's pure general, or transcendental, logic and the fundamental laws of transcendental logic are synthetic. So, neither precisification of normativity provides enough of a common conception of logic to serve as grounds for a substantive, independent dispute over whether arithmetic is analytic, which is essential to Frege's logicist thesis. ${ }^{11}$

\section{MacFarlane's normativity}

In this essay, our focus will not be on Frege's conception of logic or its normativity per se, but only MacFarlane's readings of them. I will discuss why he takes the normativity of Frege's logic to be similar to the normativity of Kant's pure general logic in this section. Then we will turn to the difference between their respective varieties of anti-psychologism, which will provide the relevant

\footnotetext{
${ }^{10}$ Another strategy one might pursue for showing Kant and Frege do not share enough of a common conception of logic for there to be a substantive dispute over logicism is to show that they mean something fundamentally different by "analytic." After all, for Kant a judgment is analytic if the predicate concept is contained in the subject concept. But, as was pointed out by an anonymous referee, if that were the relevant notion of analyticity, then Frege would agree that arithmetic isn't analytic. This point about their different conceptions of analyticity is in the background of [Anderson, 2004] and [Anderson, 2015], and it is a central topic of Michael Kremer [2006]. Important and right as these arguments are, I will not be dwelling on this dimension of difference here.

${ }^{11}$ As Kremer [2006], Reck [2013] and Keller [Forthcoming] all argue, logicism itself was understood in different ways. Russell [1938, p. 457], for example, took himself to be a logicist, but took logic to be synthetic. Here our attention will be restricted to Frege's logicism.
} 
background for my argument that Kant distinguishes two normative roles for pure general logic. Next we will develop these two kinds of normativity further by turning to Kant's distinction between pure general, and transcendental, logic. By examining how MacFarlane views this distinction, we will see that he assimilates the normativity of Kant's logic to the normativity he finds in Frege's logic. In the penultimate section, we will look at why this is problematic. And in the final section, we will turn to the second half of MacFarlane's argument and his case for maintaining pure general logic's abstraction away from objects is not fundamental to it.

To begin, although neither Kant nor Frege use the contemporary term, 'normative,' we find both deploying something like our notion. As Lanier Anderson has argued, there was a normative/descriptive divide that structured much of the German anti-psychologism debates of the late nineteenth century, ${ }^{12}$ and we find a version of the distinction in Frege. ${ }^{13}$ For Frege, normative laws say how things ought to be, and one example are moral laws. Descriptive laws say how things are, and one example are physical laws.

This conception of the normative and descriptive structures MacFarlane's account of the normativity he claims is common to Kant and Frege. He develops it by beginning with Frege. ${ }^{14}$ According to MacFarlane's Frege, logical laws are like laws of physics in that both have "the form 'such and such is the case,' not 'one should think in such and such a way.'" 15 Nonetheless, both have normative consequences: the laws of physics, for thought about the physical world, and the laws of logic for thought as such. ${ }^{16}$ Frege claims that the laws of logic "only

\footnotetext{
${ }^{12}$ [Anderson, 2005]

13 [Frege, 1893, p. xv] \& [Frege, 1918, p. 58].

14 [MacFarlane, 2002, p. 32-37; 43-44]. Although there is surely a sense in which Kant belongs within the lineage of the nineteenth century distinction, Matthew Boyle [2020] presents a nice argument that the version of this distinction found in Frege does not map straightforwardly on to a corresponding distinction in Kant.

15 [MacFarlane, 2002, p. 35]

16 [MacFarlane, 2002, p. 37]
} 
deserve the name 'law of thought' with more right [than the laws of physics] if it should be meant by this that they are the most general laws, which prescribe universally how one should think if one is to think at all." ${ }^{17}$ On the basis of this and related statements, MacFarlane argues that for Frege the defining characteristic of logic is its normativity for thought as such. ${ }^{18}$

For Kant, the logic in question is what he calls 'pure general logic' and if we turn to its titular features we will see why MacFarlane takes the defining characteristic of this logic to also be its normativity for thought as such. First, its generality. MacFarlane takes Kant's distinction between general and particular logics to track the same distinction as the one Frege was getting at with his distinction between the rules for thinking about physical things and the rules for thinking in general. This is because Kant's particular logic of physics will study the rules for thinking about physical objects, while his pure general logic will study the rules for thought as such. ${ }^{19}$ On these grounds, MacFarlane concludes that both Frege's quantificational logic and Kant's pure general logic are normative in the same way: they both provide unconditional norms for any thinking whatsoever. ${ }^{20}$

Second, although MacFarlane does not use Kant's distinction between applied and pure logic to make his case, he could have, because when Kant draws this distinction he often seems to deploy a normative/descriptive contrast. Logic will be "applied if it is directed to the rules of the use of the understanding under the subjective empirical conditions that psychology teaches us." ${ }^{21}$ This logic, which is really a branch of empirical psychology, ${ }^{22}$ describes "how thinking

\footnotetext{
17 [Frege, 1893, p. xv]

18 [MacFarlane, 2002, p. 32-44]

19 (A52/B76; JL, 9:12; Log-Pö, 24:502)

20 [MacFarlane, 2002, p. 43]

21 (A53/B77)

${ }^{22}$ At points Kant will even claim that applied logic is not properly called logic (Log-Pö, 24:507), despite discussing topics like the sources of prejudice (e.g., Log- $D, 24: 737 f f$ ), which are squarely in the realm of applied logic, in his logic lectures.
} 
does take place and how it is" in actual human beings. ${ }^{23}$ In pure logic, however, "we abstract from all empirical conditions under which our understanding is exercised." ${ }^{24}$ Its "rules are not ones according to which we think, but [ones] according to which we ought to think." ${ }^{25}$ In these passages, then, we see Kant carving off the descriptive, empirical, psychological study of the rules of our thinking, from the normative, a priori science of logic proper. And so, to the right ear, these passages, too, will have a Fregean ring. ${ }^{26}$

According to MacFarlane, then, Kant and Frege demarcate logic in the same way. He holds for Frege logic is at root descriptive, while for Kant it is not. Nonetheless, MacFarlane claims Frege demarcates which laws belong to logic through the unconditional, a priori normative laws that these descriptive laws produce. And because Kant thinks of logic as studying such unconditional, $a$ priori laws, they will agree on what determines which laws fall within logic's purview, even if they might disagree about the ultimate nature of these laws.

\section{Anti-psychologism}

Despite this apparently shared 'generality' and 'purity' of Kant's and Frege's logics, we will see that the 'normativity' that we can justifiably attribute to Kant's pure general logic is not the same as Frege's (or our own). Something that should immediately give us pause is that logic for Kant studies the rules of the understanding - the faculty for thinking - while we, with Frege, banish faculties from logic. This difference can seem subtle, but it will turn out that Kant distinguishes between two ways pure general logic is normative because

${ }^{26}$ N.B. Although Kant often deploys a descriptive/normative contrast when distinguishing applied from pure general logic, these contrasts do not perfectly align. For example, one place Kant claims applied logic also has a normative part is $J L, 9: 18$.
} 
he holds on to a central place for the faculty for thinking in logic.

Does Frege, however, really banish the faculty for thinking and judgment from logic? He holds that logic studies inference and inferential justification by identifying basic logical laws, from which logical inferences follow. These justification relations obtain independently of specific acts of thinking by any given thinker, or even independently of the faculties for thinking of all thinkers. Nonetheless, inferences are acts of mind, and so one might object to my characterization of Frege as banishing faculties for thinking and knowing on these grounds. This objection might then be bolstered by appealing to Frege's essay "The Thought." After all, there Frege famously suggests that the tasks of logic and mathematics could perhaps be represented "as the investigation of the mind; of the mind, not minds." ${ }^{27}$ And this, too, can make it sound like logic is the study of the laws governing the faculty for thinking in general.

Viewed this way, it can look as though Frege's account is not so different from Kant's. Kant also holds logic is independent of specific acts of thinking, and as many have noted, Kant too is an anti-psychologist about logic. ${ }^{28}$ He holds logic studies neither the empirical nature of this or that particular kind of thinking being (as in Locke's empirical psychology), nor the rational nature essential to any thinking being (as in Descartes's rational psychology). Nonetheless, Kant does hold that logic is "the science of the rules of the understanding in general," where the understanding is the faculty for thinking and judging. ${ }^{29}$ In this sense, for Kant, although logic does not study the (empirical or rational) nature of thinking beings or the specific acts of thinking by individual thinkers, it is concerned with the necessary rules constitutively governing any faculty of

\footnotetext{
27 [Frege, 1918, p. 74]

${ }^{28}$ E.g., Putnam [1994, p. 246], Conant [1992, p. 130ff], Longuenesse [2005, p. 89-90], and Anderson [2005, esp. 297].

${ }^{29}$ (A52/B76). Here Kant has in mind the understanding in his "broad designation," which incorporates all of the higher faculties of cognition: "understanding, the power of judgment, and reason" (A130-131/B169; also, Log-P̈̈, 24:505). In general, throughout this essay it is the understanding in this broad sense, not the narrow one, that we will be examining.
} 
thinking and its acts. And in this sense logic is not independent of the thinking subject or the faculty for thinking.

So should we understand Frege's talk of logic studying "the mind," as synonymous to Kant's talk of logic studying "the understanding"? I think that if we examine Frege's account more closely, we can see that we shouldn't. Despite first appearances, "the mind" is not a faculty for thinking. In "the Thought" Frege is distinguishing between grasping thoughts and the thoughts themselves. Thoughts, he claims, are like objects such as tables and stars, in that they are commonly available to all thinkers and knowers; nonetheless, he holds they are also unlike such physical objects, in that we cannot see them and they don't take up space. ${ }^{30}$ In this way, they are abstract objects; they are propositional contents with self-standing existence, independent of their being grasped. Grasping thoughts is thinking, and it presupposes someone who is thinking. But neither this subject nor the act of thinking is the thought grasped. And when Frege claims that logic studies "the mind" he seems to be claiming that it studies thoughts and their relationships, rather than the subjects who grasp thoughts or the faculty they have for doing so. The acts and faculties of judgment and thinking, of course, will have a central role for us as thinking and judging beings, but at least in "the Thought," logic is first and foremost about mind independent propositional contents. ${ }^{31}$

This difference over the task of logic can seem subtle. After all, both Kant and Frege abstract away from acts of thinking by individual thinkers and away from the human faculty of thinking. Its just that according to Frege, logic studies the justificatory relations between the objects of thinking - thoughtswhile according to Kant, logic studies the laws constitutively governing any

\footnotetext{
30 [Frege, 1918, p. 74]

${ }^{31}$ Whether this is ultimately Frege's view of logic is a subtle question that we will not settle here. For some recent discussion, see Mark Textor [2010a], Maria van der Schaar [2018]. For another interpreter making a similar case about Frege's view in "the Thought," see Conant [2020, esp. pt. II, §VIII].
} 
faculty for thinking and its acts. ${ }^{32}$ Yet, if MacFarlane is right, then for Frege we still identify the descriptive laws governing the logical justification relations between thoughts through the normative rules they have for all thinkers. And so he argues Frege and Kant are in agreement as far as how they would identify the laws of logic. As we will see, however, one ramification of Kant's claim that logic studies the laws of the faculty of thinking and judgment is that he holds logic is normative in two ways. And this, it will turn out, is sufficient to show that MacFarlane's supposed common ground is not fit for purpose.

\section{Two kinds of normativity of pure general logic}

Turning to the normativity of pure general logic, let's set aside the issue of whether pure general logic is normative at all, and grant to MacFarlane that it is. ${ }^{33}$ The core of the case that pure general logic is normative rests on Kant's consistent claims that it is a "canon." ${ }^{4}$ For Kant a canon is "the sum total of the a priori principles of the correct use of certain cognitive faculties in general." 35 This will be one dimension of the normativity of logic that we will want to examine: its normativity for the faculty of thinking. A second dimension of pure general logic's normativity is as an "outer courtyard" or preparatory "propaedeutic" to other sciences. ${ }^{36}$ Thoughts, as cognitions, are about objects,

\footnotetext{
${ }^{32}$ James Conant [2020] and Alexandra Newton [2020] get at this difference through the same analogy. They hold that on Frege's view thoughts begin as something dead that need life breathed into them, like some Frankenstein creature, whereas for Kant thoughts are essentially alive. As an interpretation of Kant on this point, Newton's position is more developed, however, since it can accommodate Kant's distinction between mere thinking and problematic judgment.

${ }^{33} \mathrm{We}$ are not, of course, settling the deeper disagreements that I mentioned in note 8 above over whether acts of thinking must conform to logic's rules or the way in which logic is constitutive for thinking. Notice, however, that even if the normativist reading turns out to be incorrect, interpreters will still need to account for how logic can be both a canon and a propaedeutic, and so why pure general logic at least seems to be normative in each of these ways.

34 (e.g., A53/B77)

$35(\mathrm{~A} 796 / \mathrm{B} 824)$

${ }^{36}$ (Bix, Log-W, 24:794, Log-D, 24:694; JL, 9:13, 18).
} 
and they aim at representing these correctly. For this reason, they belong to material sciences that treat this or that object, and agreement with the laws of logic is a condition on thoughts serving their purpose in such sciences.

In order to understand these two kinds of normativity of pure general logicas a canon and as a propaedeutic - we need to examine the nature of thinking and the faculty for it according to Kant. He holds thinking is cognition (Erkenntnis). It is grounded in the understanding, or the faculty for thinking, which is a faculty for cognition (Erkenntnisvermögen). And as cognition or knowledge, thoughts will have an object, something that they represent. Thus, Kant holds there are two sides to thoughts: (i) their relation to the subject's faculty of thinking, of which they are an exercise, and (ii) their relation to their object, the thing that they represent. We find Kant relying on this distinction, say, in his account of subjective and objective validity, ${ }^{37}$ or in his references to the subjective and objective deductions of the categories. ${ }^{38}$ In Kant's logical works we also find him distinguishing between this twofold relation of cognitions. ${ }^{39}$ And this is the source of the twofold normativity of pure general logic: its normativity for exercising the faculty of thinking, as a canon, and its normativity for thinking about objects, as a propaedeutic.

Notice, however, that the relations thoughts stand in to the thinking subject and the object thought about are quite different. Thinking is combining representations, paradigmatically: of judgments into inferences, of concepts into judgments, and of intuitions into concepts. Remember Kant holds the thinking being has no place in logic, but that logic studies the laws of the faculty for thinking - the faculty for combining representations into concepts, judgments, and inferences. Thus, the relation in question of the subject to its thought is not so much the relation between a maker - a being - and the thing made, but

\footnotetext{
${ }^{37}(P, \S 18-22,4: 297-305)$

38 (e.g., Axvii)

$39($ Log-Pö, 24:510; Log-Bu, 24:616; JL, 9:33, 9:58; R1693 1773-77)
} 
the relation of a faculty to its own act or exercise. The object thought about or cognized, however, is paradigmatically one that we can experience that exists independently of us, and which we did not create. And even for objects of cognition that are not separate from us, like an image of a triangle, or consciousness of the moral law, these objects depend essentially on a cognitive faculty separate from the mere faculty for thinking, be it our imagination or our will. So at least as long as we set aside the special case of logic, which is "a self-cognition of the understanding and of reason," ${ }^{40}$ the subjective relation in thinking is between a faculty and its act, while the objective relation is between this act and something outside the faculty that produced it.

Now to separate these two kinds of normativity, there is an analogy Kant often relies upon that can help. The understanding has a function- - to combine representations - and thoughts are exercises of this function, they are acts of combining. ${ }^{41}$. In this respect the understanding is like an organ, e.g., the heart, and thoughts are like acts of an organ, like pumps. When the heart functions correctly - when it is unimpeded - it circulates blood and thereby contributes to the overall wellbeing of the organism. In this respect, the understanding is similar. When it functions correctly-when it is unimpeded-it combines representations into whole thoughts that contribute to the overall system of knowledge. In both cases, the organ and the faculty have a function, and in their acts they each contribute to the whole of which they are a part. ${ }^{42}$

\footnotetext{
${ }^{40}(J L, 9: 14)$

41 (e.g., A68/B93; B130)

${ }^{42}$ Throughout his work Kant relies on such analogies between cognitive faculties or capacities and organs, or between whole systems of knowledge (sciences) and the systematic unity of organisms. For example, see Bxxiii, A835/B863, A66/B91, or $K U, 5: 375$. We have the idea of a system of ends, however obscurely, because we act for ends and because of the selfdevelopment of our own reason $(K U, 5: 375$, A835/B863). Kant holds we come to understand the systematic causal structure of organisms in part through the analogy with our own ends and powers. And for this reason, in relying on this analogy to explain the relation of cognitive faculties, we run the risk of explaining the obscure with the more obscure. We can take some solace, however, in Kant's thought that it is through this kind of procedure that we can gradually clarify the systematic idea of a science (A834/B862). I have examined Kant's account of the causal structure of organisms in more detail in my [Forthcoming], and for
} 
Just as the laws of cardiology dictate how the heart should act, the laws of logic dictate how the understanding should act. This analogy can help us distinguish the role of pure general logic as a canon and as a propaedeutic. This is because the purpose of an organ can be characterized in two ways: (i) in relation to the organ itself, and (ii) in relation to the whole organism of which the organ is a part. One could say, for example, that the purpose of the heart is (i) to pump, and (ii) to circulate blood. Similarly, one could say that the purpose of the understanding is (i) to combine representations or (ii) to cognize objects. And just as one could assess, say, the heart as to whether it is fulfilling its local purpose or contributing properly to the body overall, one can assess the understanding as to whether it is properly combining representations or is contributing properly to the cognition of objects.

Using this analogy we can see more clearly why pure general logic is a canon and a propaedeutic. Canons give rules for the correct use of a faculty, in this case the understanding. ${ }^{43}$ As a canon for the understanding pure general logic provides rules for the understanding's agreement with itself, or rules governing the way that representations get combined into thoughts. ${ }^{44}$ This is analogous to considering the heart on its own and the rules governing its acts apart from its role in the whole organism. We will arrive at these rules through the "mere analysis of the actions of [the understanding or] reason into their moments, without taking into consideration the particular nature of the cognition about

further discussion of the analogy between organisms and reason, see Breitenbach [2009, esp. ch. 4].

It is also worth noting that although Kant often speaks of 'functions' in relation to the acts of the understanding, and it is fairly clear he has the analogy with organs in mind, he only speaks of the 'function' of a part of a system once in the Critique of Teleology ( $K U, 5: 375 \mathrm{n})$. For this reason I have preferred to follow Kant in speaking of a 'purpose' or 'end' ('Zweck'), rather than a function, in the comparison below. (A further advantage of avoiding 'function' is that this practice minimizes potential confusions with contemporary notions of function, like those of Cummins [1975] or Millikan [1989], which I will not discuss.)

43 (A796/B824)

44 (e.g., A53/B77, A59/B84) 
which it is employed." 45 That is, we will examine acts of combining representations into thoughts to find rules governing when these acts are successful or defective, considered on their own, merely as acts of thinking. In this sense, as a canon, pure general logic provides norms for combining representations into thoughts, setting aside their ultimate end: cognizing objects. In this the laws of pure general logic are "conditions under which the understanding can and ought to agree with itself alone." 46 And as a canon, pure general logic is normative for the understanding looking inward at its own acts, apart from whatever use in cognition these thoughts may have.

A "propaedeutic" to a science is preparatory; it provides rules cognitions must satisfy, if they are to be true of the objects the science studies. As a propaedeutic or "outer courtyard" to the sciences pure general logic provides such criteria for "the form of truth." 47 Truth "is the agreement of cognition with its object." 48 And a minimal requirement on such agreement is that the cognition in question agree with the laws of logic. ${ }^{49}$ This is analogous to considering the heart, and the rules governing its acts, not on their own, but in relation to the whole organism. This is because as a propaedeutic logic looks past the understanding's own operation, towards its role in cognition, in developing the whole system of our knowledge. Material sciences, like physics, mathematics, or morals, are bodies of cognitions: systems of interconnected representations of a specific kind of object..$^{50}$ These component cognitions are true of their objects.

\footnotetext{
45(A131/B170; Log-Ph, 24:316). For a more detailed discussion of this passage and how pure general logic is an analysis of the faculty of thinking, see my [2020].

${ }^{46}(J L, 9: 13)$

47 (A59/B84; Bix, Log-W, 24:794, Log-D, 24:694; JL, 9:13, 18).)

48 (A58/B83). More precisely: material or objective truth. At times, Kant will contrast this with "formal truth" ( $J L, 9: 51)$. Unlike our contemporary notion of formal or logical truth, Kant's formal truths need not be true. Rather, they only need to agree with the formal criteria of truth "in complete abstraction from all objects whatsoever" ( $J L, 9: 51)$, and may still conflict with their object. Nonetheless, since formal truth - or agreement with the laws of logic - is a condition on material truth, these laws are also normative for material truth.

49 (A59/B84)

${ }^{50}$ (compare, GMM, 4:387)
} 
And logic is a propaedeutic to these sciences since violating logic's laws makes it impossible for a cognition to be true of the object it purports to represent. Or, put another way, as a propaedeutic to other sciences, logic's laws serve as minimal criteria of truth the violation of which will render the cognition false, no matter the science to which this thought belongs. ${ }^{51}$ So as a propaedeutic to other sciences, pure general logic looks beyond itself, beyond the understanding merely in isolation, towards the use of thoughts as cognitions of objects. ${ }^{52}$

With this distinction between the normativity of pure general logic as a canon and as a propaedeutic in mind, however, we might wonder if these two kinds of normativity are really so different. After all, consider the rules governing the heart. These will be the same regardless of whether we characterize its activity in relation to itself or the whole organism. Either way, for example, the heart of an elephant should pump around 30 times per second..$^{53}$ And similarly, on either way of viewing the acts of the understanding, thoughts should not contradict themselves. For example, either way, we should not (a) create concepts like $<$ bright darkness $>,{ }^{54}$ (b) judge both that a composite substance must consist of simple parts and that a composite substance must not consist of simple parts, ${ }^{55}$ or (c) be tricked into holding that "all Englishmen are men," "the respondent is a man," therefore "the respondent is an Englishman." 56 With each of these prescriptions, we could explain why they hold both (i) because the

${ }^{52}$ For more on how I take Kant to understand the distinction between formal and material sciences see my [MS].

${ }^{53}$ We can dig into this claim through two cases. Suppose in a vivisection, one could remove the beating heart and keep it pumping blood. Here the organ could continue to pump, even though it would no longer circulate blood throughout the body. Still, the organ is characteristically part of a specific organism, and although it is no longer in that organism, the rules governing its acts, were it within the organism, do not change. Second, consider Socrates's body after he has drunk the hemlock. For a time his heart pumps quite well considered on its own, yet it is also spreading the poison and harming the body of which it is a part. Nonetheless, as the heart, it should still pump blood to the extremities: it is the blood that should not be poisoned, not the heart that shouldn't pump it. So in this case too, the acts prescribed by the heart's purpose, both internally and externally, remain the same.

${ }^{54}$ E.g., Met-M, 29:792

${ }^{55}$ E.g., $P, 4: 340$

${ }^{56}$ E.g., $\log -W, 24: 828$
} 
act of combining representations into a whole thought is faulty and (ii) because such failed combinations cannot be true of an object. ${ }^{57}$

The fact that the prescriptions for the faculty of thinking are the same from both perspectives is, perhaps, not surprising. After all, the same science is in question: pure general logic. Why, then, are the two kinds of normativity different, despite the fact that the prescriptions for the understanding are the same? As a canon, pure general logic provides rules for combining representations into whole thoughts, rules with which a thought must be in agreement, if it is not going to have parts that cannot really be combined with one another because they are opposed. As a propaedeutic it provides rules that are a conditio sine

\footnotetext{
${ }^{57}$ Although what is prescribed is the same, the norms themselves will differ. (i) For example, (a) <brightness $>$ and <darkness $>$ are opposites (entgegengesetzt) and thinking fails when it attempts to posit (setzen) such marks in one concept. (b) If I am lead to such opposed judgements, then there is conflict or disunity in my system of judgments, I am not at one with myself, or as we say, I am of two minds. And (c) if I am tricked into this, then I have attempted modus ponens, but affirmed the consequent, and my infelicitous inference attempts to unite judgments in one kind of act, but at best unites them in another, and so is not true to the act undertaken. (ii) Further, (a) the form of a concept is generality - it is the type of representation that can be true of many objects-but <bright darkness $>$ cannot be true of anything; because <brightness $>$ and $<$ darkness $>$ cancel each other, it is not the kind of representation that anything can fall under. (b) Contradictory judgments, or judgments that apply two opposed predicates to a thing, cannot both be true of that thing, and cannot both belong to the same whole science. And (c) if I maintain an infelicitous inference, then I hold the conclusion is explained by the premises in a way that it isn't, and so while the conclusion may be true, I am at least wrong about the reason why it would be true. The failures of (i), then, are failures to combine representations in the way that the act should have combined them - they are not true to form - and (ii) are failures to combine representations in a way that could be true of their object, the thing they purport to represent.

Notice, violating the law of contradiction is not just attempting to combine two opposed predicates in one judgment, as Frege would hold. Rather, to violate the law of contradiction is for a power, the understanding, to violate the laws that constitutively govern this power in one of its exercises, and this can include infelicitous inferences. A further difference that deserves immediate attention is that according to Frege there is no problem with even explicitly contradictory thoughts of the form $\ulcorner P$ \& not $P\urcorner$ so long as they are mere thoughts and not judgments. This feature of Frege's logic is critical to its mathematical power. Yet for Kant, there is a problem with merely thinking of (a) a concept with marks of the form $\ulcorner A\urcorner$ and $\ulcorner$ non-A $\urcorner$ (b) a propositional content with the form $\ulcorner P \&$ not $P\urcorner$, or (c) an inference that attempts modus ponens, but affirms the consequent. In each case, thinking is divided against itself. Still, Kant does hold that such contradictory thoughts can be considered, and we can see what follows from them (see Eberhard, 8:193-4n). In part for these reasons it would be a mistake to treat pure general logic's rules, as a canon, as like Frege's syntactic rules for forming well formed thoughts, and to treat pure general logic's rules, as a propaedeutic, as like Frege's rules for valid inference. (I discuss failed exercises of the understanding, and the difference between self-annihilation and material falsity, in more detail in my [2019], and see Newton [2020] for an interesting discussion of the Kantian position and why it is philosophically important to hold that even contradictory thoughts are ill-formed.)
} 
qua non of truth-rules with which a cognition must be in agreement, if it is going to be true of its object. As a result, viewing pure general logic as a canon or a propaedeutic is viewing the purpose of the understanding as combining representations or as cognizing objects. And because the understanding serves both of these purposes, the laws of pure general logic will be normative either for thought's agreement with itself or for the possibility of thought's agreement with its object. So although pure general logic's prescriptions for the understanding are the same whether it is viewed as a canon or a propaedeutic, the purpose of the understanding will be different, and because it is the purpose that determines the nature of the normativity, the normativity will differ also.

We can sharpen our account of the relationship between these two kinds of normativity. Pure general logic's normativity as a canon is directed inward, towards the operations of the faculty for thinking. Its normativity as a propaedeutic is directed outward, towards objects and the whole system of sciences and knowledge. And so while as a canon, logic provides rules for the operation of the faculty, agreement with these is a condition on thinking truly. We see Kant relying on this relationship between the two kinds of normativity when he explains why the rules of pure general logic present rules of truth. There he says, "that which contradicts these [rules] is false, since the understanding thereby contradicts its general rules of thinking and thus contradicts itself." ${ }^{58}$ Here he explains why a contradictory cognition cannot be true through an appeal to the internal coherence of an act of the understanding. And so in this passage we see why he would explain the object-oriented normativity of logic as a propaedeutic in terms of its faculty-oriented normativity as a canon. We can come at this relationship from a slightly different direction if we consider, further, that logic is the science of the understanding, the faculty for thinking, but through sensibility, objects are given to be cognized. As the science of the understanding, logic

\footnotetext{
${ }^{58}$ (A59/B84, my emphasis)
} 
abstracts away from sensibility, treating thinking in isolation from its influence. Since objects are given through sensibility, pure general logic's faculty-oriented normativity as a canon is more proper to it. Once we consider that thoughts are about objects and all objects are given to thought through intuition, however, then pure general logic's normativity as a propaedeutic, its object-oriented normativity, comes into the picture. After all, "all thought as a means is directed" towards the end of intuition (A19/B33). And so it is only within this broader context that logic can serve its full purpose.

Above I claimed that it is because Kant's logic studies the acts of the understanding necessary for thinking that he distinguishes these two respects in which pure general logic is normative. Now it should be clear why: since Kant's logic studies the laws governing the faculty for thinking and its acts, it will be a canon, and since the understanding is a faculty for knowledge, it is a propaedeutic. For Frege, logic is a fundamentally descriptive science. Nonetheless, it yields normative rules for judging and inferring. Frege presents the normativity of logic as like the normativity of the laws of physics: both consist in truths about classes of objects, and since judging aims at truth, both provide norms for judging. For Kant, however, logic is not fundamentally a science of truths about objects, and its normativity is not founded in this descriptive task - neither as a canon, nor as a propaedeutic. If we press past and ignore this important difference, however, then at best it seems the normativity of Frege's logic would be close to that of a propaedeutic. But from Kant's standpoint this cannot be all there is to logic's normativity, because it misses the normativity of logic as a canon for thinking, merely as rules for combining representations into whole thoughts. And so even if the normativity of logic for thought as such were logic's defining feature for Frege, from Kant's standpoint, it is built into the Fregean conception of logic that it misunderstands the nature of this normativity. 
Still, MacFarlane might press, this is insufficient to show that not enough common ground has been identified between Kant and Frege. After all, these differences in how Kant and Frege understand the normativity of logic follow from Frege's taking logic to be a fundamentally descriptive science, while Kant rejects this, and MacFarlane acknowledges that difference. He just holds that difference does not rule out their agreeing enough on what determines which laws count as logical for them to have a substantive, independent dispute over logicism, and regardless of whether we view pure general logic as a canon or a propaedeutic, it will consist in the same prescriptions. For this reason, I'd like to turn now to a second dimension of the difference between the faculty-oriented normativity of pure general logic as a canon and the object-oriented normativity of it as a propaedeutic. Specifically, I'd like to turn to how this relates to Kant's distinction between pure general and transcendental logic. We will see that both kinds of logic, for Frege, might seem to provide norms for thought as such, and so both will fit with MacFarlane's criterion of logicality. But if this criterion cannot distinguish the laws of pure general logic from the laws of transcendental logic, then, from Kant's standpoint, there will not be enough of a shared conception of logic for there to be a substantive, independent dispute over Frege's logicism, because the fundamental laws of transcendental logic are synthetic.

\section{$5 \quad$ Transcendental and pure general logic}

Although differences in Kant's and Frege's respective kinds of anti-psychologism are one source of hesitation over the inference from the apparently shared generality and purity of their logics to their being normative in the same way, there is a remaining elephant in the room. Kant divides between two branches of logic: pure general and transcendental. Frege does not. Since transcendental logic is also a priori, it is pure. But interpreters of Kant are in disagreement over 
whether transcendental logic is also general, or whether it is a special logic. ${ }^{59}$ Either way, the fact that Kant divides these two branches of logic, while Frege does not, should give us pause. In this section we will introduce Kant's division between these logics, and examine briefly how Frege's logic wouldn't clearly be a part of either. In the next, we will turn to why MacFarlane is incorrectly dividing pure general from transcendental logic. Once this is straightened out, however, then we will see the dilemma MacFarlane's argument faces, and why Kant's and Frege's nominal agreement over the normativity of logic does not suffice for a substantive, independent dispute over whether arithmetic can be shown to be analytic through its reduction to logic.

Kant draws the division between transcendental and pure general logic in the introduction to the Transcendental Logic. Pure general logic abstracts "from all content of cognition, i.e., from any relation of it to the object, and considers only the logical form in the relation of cognitions to one another, i.e., the form of thinking in general." ${ }^{60}$ Because we can consider both empirical and a priori (or pure) intuition of objects, however, he also holds there will be empirical and pure thinking of objects. And although pure general logic abstracts away from whether a thought is empirical or pure, transcendental logic is that logic that contains "merely the rules of the pure thinking of an object." ${ }^{61}$ This logic does "not abstract from all content of cognition" and therefore concerns "the origin of our cognitions of objects insofar as they cannot be ascribed to the objects; while general logic, on the contrary, has nothing to do with this origin of cognition." ${ }^{\prime 62}$

Since Frege does not draw this division, it is not immediately clear which of these branches his logic would belong to. On the one hand, pure general

\footnotetext{
${ }^{59}$ For a nice discussion of the history of this dispute see Tolley [2012, §2].

${ }^{60}(\mathrm{~A} 55 / \mathrm{B} 79)$

$61(\mathrm{~A} 55 / \mathrm{B} 80)$

$62(\mathrm{~A} 56 / \mathrm{B} 80)$
} 
logic abstracts from the relation of cognitions to objects, while transcendental logic does not. Since Frege's logic also does not abstract away from the relation cognitions stand in to their objects, that suggests Frege's logic should belong to transcendental logic.

On the other hand, at the outset of the Foundations of Arithmetic Frege famously attacks treating the origin of cognition in logic, claiming that such a treatment would be psychologistic. If Frege and Kant mean the same thing by "origin," then that would suggest Frege's logic belongs to pure general logic and that Frege would hold Kant's transcendental logic is not logic. This seems further supported by the fact that Frege's logic governs thoughts, no matter whether their objects are empirical, like those stating empirical observations, or a priori, like the ones that figure in geometry.

Of course, Frege's logic might not count as either pure general or transcendental logic, in which case finding enough of a common conception of logic for a substantive dispute over logicism - over whether arithmetic is reducible to logic - would seem difficult. Further, if Frege's logic belongs to transcendental, not pure general logic, then it will also be difficult to find the kind of common ground MacFarlane is after. Frege considers judgments that can be justified solely through primitive logical laws to be analytic. ${ }^{63}$ Kant, however, holds the fundamental laws of transcendental logic to be synthetic. Presumably, with many of these laws Frege would agree, as with the law "everything that happens has a cause." 64 For this reason, if Frege and Kant have enough of a shared conception of logic for the kind of dispute over logicism that MacFarlane holds there to be, it looks like this shared conception will not belong to transcendental logic. And so it is no surprise that MacFarlane has made pure general logic his focus. ${ }^{65}$

\footnotetext{
63 [Frege, 1884, §3]

${ }^{64}$ (A9/B13; A189/B232)

${ }^{65}$ It is usually presumed that the laws of pure general logic are analytic. As far as I can
} 
Returning now to the distinction between logic's normativity as a canon and a propaedeutic, there is a complication that should be kept in mind. Although above my focus was on pure general logic, we can also distinguish a faculty- and an object-oriented kind of normativity for transcendental logic. After all, transcendental logic is also a logic, a canon, and a propaedeutic to other sciences. ${ }^{66}$ And as a logic and a canon, in a sense, it too studies the understanding in isolation from its objects or sensibility. Nonetheless, the way in which it studies the understanding in isolation is different: whereas pure general logic abstracts away from how objects can be given to thought, transcendental logic does not. This means that even the faculty-oriented normativity of transcendental logic is its normativity for the understanding and its actions, as we find them in thinking about objects, whereas the faculty-oriented normativity of pure general logic does not share this lingering connection to objects. Or, to put this same point in terms of intuition, the faculty-oriented normativity of transcendental logic is its normativity for thinking about and combining a manifold of a priori intuition, while pure general logic does not share this lingering connection to sensibility, and treats all representations equally as though their origin were in the understanding. For our purposes, we won't need to worry about the differences between transcendental logic's normativity as a propaedeutic and a canon, since both have this connection to objects. What will be important, however, is whether MacFarlane has the resources to distinguish the normativity of pure general logic as a propaedeutic, which is concerned with cognition's agreement find, Kant nowhere claims this. What he does claim is that the principle of contradiction is "the universal and completely sufficient principle of all analytic cognition" (A151/B191), where this means that if a judgment is analytic then "its truth must always be able to be cognized sufficiently in accordance with" this principle (A150/B191). This suggests that although as the fundamental law of pure general logic the principle of contradiction may not itself be analytic, if a judgment can be sufficiently cognized from it, then that judgment will be analytic. In this respect, Kant's view of this principle does not look so different than Frege's view of his fundamental logical laws. After all, Frege does not claim that these basic laws are themselves analytic. Rather, he only claims that truths which follow from these basic laws alone are analytic [Frege, 1884, §3].

${ }^{66}$ (A11/B25-A12/B26, A63/B88, A132/B171, A850/B878) 
with an object, from the normativity of transcendental logic.

\section{The object relatedness of pure general logic}

I would like to now turn to MacFarlane's description of the distinction between pure general and transcendental logic. We will see that MacFarlane is not attentive to the different presumptions Kant and Frege make about the place of the singular judgment form in logic. Specifically, he does not see how, for Kant, the singular judgment form does not belong to pure general logic in the strict sense, but is only distinguished from the universal judgment form when looking to transcendental logic. As a result, he misses the way that even in its normativity as a propaedeutic, pure general logic may treat the understanding in isolation from sensibility - in isolation from the objects requisite for singular judgment. And he does not see how the logical form of the discrete, denumerable object at the foundation of Frege's logic is absent from pure general logic.

MacFarlane reveals how he is thinking about the singular judgment form and the place of objects in pure general logic in the way he draws the distinction between pure general and transcendental logic. In MacFarlane's initial characterization, he rightly says, "transcendental logic supplies norms for 'the pure thinking of an object' (A55/B80, emphasis added), not norms for thought as such." 67 In an attached footnote, however, he clarifies that he takes pure general logic to supply norms for thinking of objects in general, without a spatio-temporal restriction, while transcendental logic only treats spatio-temporal objects in general. He says, "Kant seems to regard the restriction of transcendental logic to objects capable of being given in human sensibility as a domain restriction like the restriction of geometry to spatial objects." 68

\footnotetext{
${ }^{67}$ [MacFarlane, 2002, p. 48]

${ }^{68}$ [MacFarlane, 2002, p. 48, n35]. This problematic conception of the distinction between transcendental logic and pure general logic as a domain restriction is somewhat common. For
} 
There is something sound in the spirit of MacFarlane's claim. On Kant's account we can only have theoretical cognition of spatiotemporal objects of possible experience. Nonetheless, in order to critique traditional metaphysics, transcendental philosophy must address purported cognition of non-spatiotemporal objects like the soul, the cosmos, or God. In this respect, its topic includes objects that cannot be sensibly given, like God. Transcendental logic, however, also takes into account the purported origin of representations and does not abstract away from all content of cognition. As a result, it distinguishes the origin of our representations of non-sensible objects, which can only be thought about through mere ideas, from the origin of our representations of spatiotemporal objects, which we can also intuit and cognize through concepts of experience or concepts of the understanding. Thus, while theoretical cognition may only be possible of spatiotemporal objects, transcendental logic is not merely concerned with such objects, and it is misleading to characterize Kant's distinction between pure general and transcendental logic as merely restricting the domain of relevant objects to the sensible ones. A more accurate characterization lies in the fact that transcendental, but not pure general, logic considers the objects with which concepts will be used and the way in which those objects are thought.

What is significant here for our purposes is that MacFarlane thinks the supposed wider scope of pure general logic means that its laws govern all objects whatsoever, and so its domain should be assimilated to that of Frege's logic. Part of the problem with this is that it treats all thoughts for Kant as though

example, as Tolley [2012, p. 421, n6] points out, both Jay Rosenberg [2005, p. 90] and Jill Buroker [2006, p. 79] seem committed to it. Another example seems to be Wayne Waxman. He holds the topic of transcendental logic - the objective unity of apperception - develops out of the "mere unity of sensibility" [Waxman, 2013, p. 401], which he holds is essentially spatiotemporal [Waxman, 2013, ch.2]. Finally, Jim Conant [2020, p. 602] seems to endorse it too: "Logic is concerned specifically with the theoretical faculty of the understanding. Its task is to articulate the form of that faculty. The task of pure general logic is to articulate that form considered in abstraction from any relation to objects and that of transcendental logic to articulate it in relation to sensible matter." 
they were thoughts about objects — - be they sensible or not—when it is important for Kant that some thoughts are not about the kind of countable entities Frege has in mind. For example, the good, or the synthetic unity of apperception, are not countable quantities. Yet we can both think and judge about them, and these judgments are subject to the laws of pure general logic. ${ }^{69}$

There is, however, an additional deeper problem. Even if pure general and transcendental logic were concerned only with the theoretical use of reason and the thoughts they governed were the same, MacFarlane's view would still get the nature of the normativity of pure general logic wrong. It would treat this logic as though it were more like transcendental logic than it is. And as we will see, it is only within the context of this misconception that the assimilation of the normativity of pure general logic to that of Frege's logic can look attractive.

To see this, first consider that the quantificational structure of Frege's logic builds in that concepts divide their referents and that Frege holds thought as such is about discrete objects. Kant's pure general logic does not do this. Rather, for Kant, it is transcendental logic that studies the laws of thinking about objects in general. Indeed, the form of singular judgments only cleaves from universal judgments once we look beyond pure general logic and towards transcendental logic. Kant does this explicitly in the first Critique's table of the logical functions of thinking in judgments. In the ensuing remarks he makes clear that he holds logicians who are only concerned with "the use of judgments with respect to each other" are right not to distinguish these, and that it is only when we look beyond the internal validity of judgments to their nature as cognitions, or representations of an object, that this distinction is required. ${ }^{70}$

\footnotetext{
${ }^{69}$ See Tolley [2013] for a fuller development of this point that pure general logic has a wider application than does Frege's quantificational logic.

70 (A70/B85-A71/B86). For further defense of the claim that the singular judgment form ' $F(a)$ ' does not belong to Kant's pure general logic, strictly speaking, while it is the foundational judgment form of Frege's logic, see Wolff [2007]. For a recent defense of the contrasting view, see Lu-Adler [2014]. In future work I hope to examine the place of the singular judgment form for Kant in more detail.
} 
Prior to this, logic studies only the four judgment forms of the Aristotelian square of opposition - 'all $A$ is $B$;' 'no $A$ is $B$;' 'some $A$ is $B$;' 'some $A$ is not $B$ '- together with the hypothetical and disjunctive judgment forms, and it is not supposed that thoughts will be used with discrete objects.

Returning now to the faculty- and object-oriented normativity of pure general logic, this fits comfortably with pure general logic's normativity as a canon. After all, this faculty oriented normativity abstracts away from the relation that representations stand in to their objects. And so it is no surprise that as a canon for the correct use of the understanding, strictly conceived, pure general logic will not treat the singular judgment form. But how does this point square with logic's normativity as a propaedeutic? After all, this is pure general logic's normativity as rules for thinking true thoughts - thoughts that are in agreement with their object. How could abstracting away from the distinction between singular and universal judgments or from singular thought and the logical form of an object, be compatible with pure general logic's normativity as a propaedeutic?

The answer lies in three different ways Kant will speak of 'objects.' In the first Critique, when Kant writes of objects, he usually has in mind either objects of experience or non-sensible objects like souls, the cosmos as a whole, or God. ${ }^{71}$ Because we can sense objects of experience, but not non-sensible objects, we will only be able to have material cognition of sensible objects, although we will be able to think about both through the categories, as is evident in the principles of the understanding, the four paralogisms, the four antinomies, or the three possible proofs of God's existence.

Less frequently, however, he will speak of objects in a more minimal sense, and it is the contrast between this minimal sense of object and the two more standard senses that will be significant for us. This minimal concept of an ob-

\footnotetext{
${ }^{71}$ E.g., (Bxxviii)
} 
ject in general "leaves undecided whether it is a something or a nothing." 72 One example of a 'nothing' is a two-sided enclosed figure. Kant took the object of the concept $<$ two-sided enclosed figure $>$ to be a nothing because it was not constructible. Concepts like this will have the bare thematic unity required of any concept, ${ }^{73}$ but are not determinate enough to be used in thinking true affirmative thoughts about their objects through categories like quantity, quality, or substance. So while such concepts have a topic, or a subject matter, being about something in this sense does not entail that this subject matter is composed of discrete, countable individuals. This, however, is critical for the plausibility of the reduction of arithmetic to logic. After all, Frege's reduction depends on concepts dividing their referents, and that requires the concepts are true of discrete countable objects.

How does this help us in understanding pure general logic's normativity as a propaedeutic for thinking true thoughts about objects? Well, in pure general logic's nominal explanation of truth as "the agreement of cognition with its object" there is an interpretive question about which sense of 'object' Kant has in mind. ${ }^{74}$ We might, on the one hand, claim the object in question leaves undetermined whether it is a something or a nothing or, on the other, we might hold that the objects in question must at least be thinkable through the categories. The placement of the discussion of truth in the introduction to the transcendental logic, could be taken as suggesting that the kind of truth that is primarily in question is truth about objects, in the more robust thinkablethrough-the-categories sense, just as how there we will distinguish singular from universal judgments. But just as pure general logic proper, now not with an eye towards its use in transcendental logic, does not distinguish singular from universal judgment, there is a case to be made that the notion of truth proper

\footnotetext{
$72\left(\mathrm{~A} 290 / \mathrm{B} 346 ;\right.$ Met $\left.-L_{2}, 28: 543\right)$

73 (see B114)

74 (A58/B83-A59/B84)
} 
to it will also apply to representations that may not concern objects that can be thought through the categories. And if pure general logic's normativity as a propaedeutic were understood as its normativity for thinking true thoughts, only in agreement with this weaker notion of an object, then logic would have no problem abstracting away from the distinction between singular and universal judgments, while still being normative as a propaedeutic.

Although I think this second suggestion is right-it is the weaker notion of object that Kant has in mind and the nominal explanation of truth that belongs to pure general logic does not presuppose the object in question is thinkable through the categories - I don't want to make that argument here. When MacFarlane uses the term 'object,' he means a countable entity - a quantity-whose name can figure in a singular proposition of the form ' $\mathrm{Fa} .{ }^{75}$ MacFarlane, like Frege, presumes that thoughts are about such discrete objects and assimilates the normativity of pure general logic to that of Frege's logic. If we understood 'object' in the weaker way, then the object-oriented normativity that stems from the nominal explanation of truth would not look enough like the normativity MacFarlane finds in Frege, since pure general logic would not treat the logical form of discrete numerable individuals, and there would be no way a logicist program could get off the ground within it. Thus, regardless of how things ultimately come out, in order to put MacFarlane on the strongest possible footing, in the nominal explanation of truth let's take Kant to mean 'object' in the more robust thinkable-through-the-categories sense.

\footnotetext{
${ }^{75}$ This Fregean conception of an object is not as robust as Kant's standard thinkablethrough-all-of-the-categories notion of an object, which requires that we be able to think about the object through all of the categories, not just quantity. Still, let's not make much of that distinction here, and grant to MacFarlane for the sake of the argument that these two notions are close enough.
} 


\section{The supposed common ground}

We can now present the dilemma facing MacFarlane. Remember, his goal is to establish that there are grounds on which one could adjudicate Kant and Frege's dispute over the plausibility of logicism - the reduction of arithmetic to logic. He argues that there are such grounds because at root Kant and Frege share the same fundamental conception of logic: it provides norms for thought as such. The major obstacle to finding such common ground, according to MacFarlane, is that Kant thinks logic abstracts away from the relation that representations stand in to their objects, while Frege does not. MacFarlane thinks that if Kant takes this to be a defining characteristic of pure general logic, then there will not be the kind of substantive shared conception of logic that he is looking for. ${ }^{76}$ His reason is that "unless Kant and Frege can agree, in general terms, about what logic is, there will be no basis [...] for saying that they are disagreeing about a single subject matter logic, as opposed to saying compatible things about two subject matters, logic Frege $_{\text {and }}$ logic Kant. "77 Thus, by MacFarlane's lights, it is critical that while the fundamental defining characteristic of pure general logic is its normativity, it is a merely derivative feature of this logic that it abstracts away from the relations representations stand in to their objects.

Now, to see why MacFarlane's argument faces the dilemma I mentioned at the outset, grant that the fundamental defining characteristic of pure general logic is that it provides norms for thinking as such. Which kind of normativity is it? On the one hand, suppose it were the object-oriented normativity of pure general logic as a propaedeutic. For the sake of argument, we've granted to MacFarlane that the object-oriented normativity of pure general logic is its normativity for thinking true thoughts about countable objects. On this construal, then, both pure general, and transcendental, logic provide norms for thinking

\footnotetext{
76 [MacFarlane, 2002, p. 30]

77 [MacFarlane, 2002, p. 28]
} 
about discrete objects in general. Thus, the object-oriented normativity of a candidate law - that it is a necessary criterion on truth - is insufficient for deciding whether the law belongs to pure general or transcendental logic. And a criterion that only distinguishes a candidate law as logical, without deciding which of these logics it belongs to, is not sufficient for establishing substantive common ground for a dispute over logicism. This is because there is only a substantive dispute if the logics in question would both count the judgements they ground as analytic. On Kant's account, however things may be with general logic, this does not hold of transcendental logic: a law that could belong to transcendental logic could be synthetic. And so a reduction of arithmetic to it would be insufficient for showing arithmetic is analytic. ${ }^{78}$

On the other hand, suppose the faculty-oriented normativity of pure general logic as a canon were definitive of it. This kind of normativity does not have a relevant correlate for Frege. Although both Kant and Frege were antipsychologists, Frege's anti-psychologism jettisoned the treatment of faculties from logic, while Kant still maintained logic treats the laws constitutively governing the faculty of thinking and its acts. But even setting this difference to one side, logic's normativity as a canon still would not do as a foundation for a substantive dispute over logicism. This is because it is essential to the faculty-oriented normativity of pure general logic that it abstracts away from

\footnotetext{
${ }^{78}$ Although Kant would likely reject a Fregean reduction of arithmetic to transcendental logic as well, we might wonder how things would look if Frege could press Kant this far. My hunch is that arithmetic in this case will look more synthetic than analytic, because to mediate the relation between the concepts in an arithmetical judgment in a way that Kant could accept, these judgments will still depend on a manifold or multiplicity from pure intuition (even if Frege could establish against Kant that this multiplicity need not be spatial or temporal). And although as Tom Ricketts [1985, p. 15, n7] notes, we cannot take too seriously Frege's endorsement of Kant's views of geometry and intuition, since Frege nominally endorses Kant's distinction between our receptive and intellectual faculties, there is a case to be made that he too is committed to distinguishing pure general logic (laws of thinking in general) from transcendental logic (the laws of thinking of objects in general). For this reason, there is also a case to be made that Frege himself is committed to his own logic being a branch of transcendental, not pure general, logic, and so a case to be made that he is committed to its judgments being synthetic, at least on Kant's construal of the analytic/synthetic distinction. To properly develop this line of thought, however, will have to wait for another occasion.
} 
objects. After all, the faculty-oriented normativity of pure general logic is its normativity as a canon for the operation of the understanding on its own, in isolation from sensibility and the objects thoughts are about. And so if it is the faculty-oriented normativity of pure general logic that is definitive, then its abstraction away from objects is not a derivative feature of it. But that is what MacFarlane's argument required. Thus, distinguishing these two ways in which pure general logic is normative blocks MacFarlane's argument.

\section{Is abstraction from objects subsidiary?}

I have been arguing that MacFarlane presupposes a more Fregean conception of the normativity of logic - after all, he assumes Frege's conception of the normative and descriptive, Frege's conception of anti-psychologism, and Frege's conception of how thinking and judging relate to objects. We have seen that if we instead conceive of these in a more Kantian way, then the agreement that MacFarlane finds between Kant and Frege over the nature of logic looks merely nominal. In the second part of MacFarlane's essay he turns to showing that when Kant claims that pure general logic abstracts away from objects, sensibility, and ontology, he is engaged in a substantive dispute with his LeibnizianWolffian predecessors over the nature of logic, and that this same substantive dispute caries over to Frege. As with Frege, MacFarlane's thought is that Kant and the Leibnizians agree over the nature of logic - its defining characteristic is that it studies the norms for thought as such-although there is a substantive dispute over whether logic abstracts away from objects. He claims that Kant's case for logic abstracting away from objects, then, depends on extralogical metaphysical commitments, and so Kant's dispute with the Leibnizians over whether logic abstracts away from objects is really one in metaphysics.

As above, however, I will argue this characterization of the difference between 
Kant's view of pure general logic and the conception of logic found in Leibniz or Wolff is not one that the critical Kant would accept. For Kant, pure general logic is the science of the laws of the understanding. A proper conception of this science, then, depends on a proper conception of the understanding, and how it is distinct from sensibility. Prior to this, from Kant's standpoint one will not have pure general logic's topic clearly in view. But if Kant is right about this, then pure general logic's abstraction away from sensibility and objects is not a feature of this logic that follows from subsidiary metaphysical commitments, but from a proper conception of logic itself. And on these grounds, I will be arguing that MacFarlane's construal of the dispute between Kant and the Leibnizians is already partisan.

Before we turn to this argument, we need to clarify how we will be disagreeing with MacFarlane. At the outset, we saw Wang and Poincaré claiming that Kant and Frege do not share enough of a conception of logic for there to be a substantive, judicable dispute over logicism. MacFarlane understands them to be claiming that the apparent dispute over logicism is "merely verbal," and that Frege "simply changed the subject." 79 This can make it seem like Wang and Poincaré think the disagreement between Kant and Frege is superficial. If we reflect on our passage above from Wang, however, I think we will see this does not ring true. In that passage Wang was claiming that the disagreement over the reducibility of arithmetic to logic cannot be detached from a deeper dispute about logic's nature - from the dispute over the place of synthetic and analytic judgments within logic. For this reason, Wang was not claiming that the dispute between Kant and Frege is merely verbal or that it is superficial. Rather, he was claiming that it is more profound than MacFarlane's interpretation allows. ${ }^{80}$

\footnotetext{
${ }^{79}$ [MacFarlane, 2002, p. 60]

${ }^{80}$ The same could be said for Poincaré $[1914$, ch. 4]. After all, as an editor for this journal points out, Poincaré held that Russell's logic incorporated appeals to intuition. And even if Poincaré's 'intuition' was quite different than Kant's, they can surely agree that the disagreement over logic's nature is deeper than MacFarlane's interpretation allows.
} 
The dispute between Kant and the Leibnizians over whether logic abstracts away from objects is similar. I think MacFarlane is right that this disagreement is substantive. In fact, I think it is more substantive than MacFarlane is making it out to be. MacFarlane argues that this dispute is accidental to their respective conceptions of logic: that Kant and the Leibnizians agree on the essence of logic, but they disagree on whether logic has the subsidiary feature of abstracting away from objects. We will see, however, that this mischaracterizes the nature of the dispute from Kant's mature standpoint. For Kant, it is not merely a dispute over whether logic, per accidens, abstracts away from objects, but over whether it is essential to logic that it abstracts away from them.

There are three parts to MacFarlane's case for why pure general logic's abstraction away from objects is a merely derivative feature of it, and in replying I would like to briefly address each. First, I will look at the text from the Jäsche Logic that MacFarlane appeals to as motivation. Second, I will examine MacFarlane's historical claim that in Kant's pre-critical discussions of logic, he takes logic to be essentially normative but not to abstract away from objects. Third, I will briefly evaluate MacFarlane's philosophical reconstruction of how Kant might have argued from logic's normativity to its abstraction away from objects. What we will see is that in each case the same evidence, but viewed from the standpoint of Kant's mature philosophy, will yield a conclusion opposite to the one MacFarlane comes to. We will see that from this standpoint, it is only once one recognizes that logic abstracts away from objects that one has properly understood logic's topic. And we will see that the more Fregean standpoint MacFarlane occupies has led him to see pure general logic's abstraction away from objects as grounded in extra-logical commitments, whereas from the standpoint of Kant's critical philosophy this abstraction away from objects is part of a proper understanding of pure general logic as the science of the 
understanding.

The main text in which MacFarlane claims to find Kant inferring from logic's normativity to its abstraction from the objective content of thought is:

[1] If now we put aside all cognition that we have to borrow from objects and merely reflect on the use just of the understanding, we discover those of its rules which are necessary without qualification, for every purpose and without regard to any particular objects of thought, because without them we would not think at all. [2] Thus we can have insight into these rules a priori, i.e., independent of all experience, because they contain merely the conditions for the use of the understanding in general, without distinction among its objects, be that use pure or empirical. [3] And from this it follows at the same time that the universal and necessary rules of thought in general can concern merely its form and not in any way its matter. [4] Accordingly, the science that contains these universal and necessary rules is merely a science of the form of our cognition through the understanding, or of thought. ${ }^{81}$

According to MacFarlane, [1] expresses logic's normativity for thought as such, while [3] infers from this that logic will abstract from the objective content of thought. On this reading it is crucial that Kant is only discussing logic's normativity in [1], not its abstraction from objects. But Kant explicitly says in [1] that he is putting "aside all cognition that we have to borrow from objects." So the text does not bear out MacFarlane's interpretation: in [1] Kant is already abstracting away from objects. ${ }^{82}$

We should read this passage instead as follows. In the transition to [3], Kant is not drawing an inference, so much as unpacking information that was already included in [1], through an implicit contrast between pure general and transcendental logic. In [1] Kant is giving a standard faculty-oriented characterization of pure general logic through its relation to the understanding. In

\footnotetext{
${ }^{81}$ (JL, 9:12, boldface MacFarlane). See also [MacFarlane, 2002, p. 46].

${ }^{82}$ To this, one might object that in [1] Kant is adverting to the discussion of the prior paragraph, and has in mind what can be borrowed from particular kinds of objects-i.e. particular subject matters. While Kant is picking up on the discussion of the last paragraph, this only threatens my point if the concepts involved in thinking about any subject matter must divide their reference. But as we've seen, this is a Fregean presumption foreign to Kant.
} 
[2] he is implicitly contrasting pure general with transcendental logic through his qualification that here the use is "pure or empirical." This is because in transcendental logic it is only pure. ${ }^{83}$ Then in [3] he is developing this contrast further by making explicit that pure general logic concerns merely the form of thoughts, while implying that transcendental logic also concerns their matter. So pure general logic's abstraction away from the material of thought is already implicit in [1], although through the implicit contrast with transcendental logic it is thrown into sharper relief in [3].

Turning to MacFarlane's historical evidence, he claims that while Kant characterizes logic through its normativity in both his pre-critical and critical writings, he only maintains logic abstracts away from objects in the critical writings. MacFarlane concludes from this that Kant's fundamental conception of logic stems from its normativity for thought in general, while its formality is a merely derivative feature that only follows from Kant's critical metaphysics. ${ }^{84}$

I think we should grant MacFarlane the textual point. Nonetheless, his conclusion is unwarranted. As Kant is arriving at his critical insights in the early 1770 s, he is also recognizing the exact contours of the mature distinction between inner-sense and apperception. ${ }^{85}$ And so in the 1770s Kant is also arriving at his mature conception of the distinction between understanding and sensibility. But if logic for Kant is essentially "the science of the rules of the

\footnotetext{
${ }^{83}$ (B79/A55-B82/A57)

${ }^{84}$ [MacFarlane, 2002, p. 53-57]

${ }^{85}$ This is a large claim that I cannot properly defend here. But because I do not know of anyone who lays out this development, briefly, if you look at Kant's discussions of inner sense and apperception through out the pre-critical writings, it is clear that he is not distinguishing them. For example, in the early False Subtlety essay he says, "If one succeeds in understanding what the mysterious power is which makes judging possible, one will have solved the problem. My present opinion tends to the view that this power or capacity is nothing other than the faculty of inner sense, that is to say, the faculty of making one's own representations the objects of one's thought (FS, 2:60; also Met- $\left.L_{1}, 28: 276\right)$. But by the time we get to the first Critique it is crucial that Kant, unlike "in the systems of psychology" in which it is customary "to treat inner sense as the same as the faculty of apperception," carefully distinguishes between these (B153). The latter of which, as pure apperception, he even identifies with the understanding (B134n, A117n; B154; Met-Mr, 29:889; Anth, 7:142; 7:134n; 7:161).
} 
understanding in general," 86 and it is essential to pure general logic that it studies these in isolation from sensibility, then since Kant lacks his mature distinction between understanding and sensibility prior to the 1770 s, prior to this he also lacks his mature conception of pure general logic. So while it may be that Kant only claims pure general logic abstracts away from objects in his critical writings, rather than taking this as evidence that such abstraction was inessential to logic, we could conclude that prior to his critical turn Kant lacked his mature conception of pure general logic.

This would be the appropriate conclusion from Kant's perspective. For one, the first principles of his mature philosophy are clearly his cognitive faculties, as is evident insofar as all three of his Critiques consist in analyses of these. So rather than there being some faculty independent conception of logic through its normativity for thought, the faculties and their relationships are the key to logic's nature according to Kant's mature philosophy. Further, for another, this would also be the appropriate conclusion according to his pre-critical philosophy. MacFarlane is right that Kant is picking up his conception of logic from the tradition, as general rules or norms for thinking. But more precisely, Kant is picking up the traditional conception of logic as necessary rules governing the understanding in general. Although MacFarlane does not draw attention to the faculty oriented nature of this normativity, throughout his life Kant defined logic as "a science that teaches us the use of the understanding." 87 And so throughout his life he would have taken the essential characterization of logic to have been in terms of the understanding. What shifts is his conception of this faculty and his recognition that any knowledge of multiplicity must come through sensibility. But even the pre-critical Kant would agree that the proper conception of logic is grounded in the proper conception of the understanding,

\footnotetext{
${ }^{86}$ (A52/B76)

$87(\log -B l, 24: 28,1771)$
} 
and so should agree that one only has the former once one has the latter.

Finally, similar considerations will apply to MacFarlane's philosophical reconstruction of why extra logical commitments lead Kant to hold that pure general logic abstracts away from objects. If we take seriously Kant's characterizations of logic as the science of the understanding in general, we will recognize these supposedly extra-logical commitments are part of a proper conception of pure general logic, not external features of it. This is because rather than having to do with his metaphysical doctrines - e.g., his transcendental idealism-these supposedly "extra-logical" commitments concern the exact relation between understanding and sensibility. But as I've been arguing, this relation is part and parcel with what Kant takes logic to be. We can see that these commitments concern this relation through the two "lemmas" that MacFarlane claims bridge the gap between pure general logic's normativity and its abstraction from objects. For example, one lemma is that "general logic must abstract entirely from the relation of thought to sensibility." ${ }^{8}$ This is supposed to follow from the normativity of logic as such, and the claim that "thought (thinking) is intelligible independently of its relation to sensibility." ${ }^{89}$ But rather than being an extra-logical metaphysical commitment, this lemma is an aspect of the faculty oriented normativity of logic. It may be that Kant did not see precisely what this commitment entailed until he had his mature conception of the contrast between understanding and sensibility, because he did not yet see that only sensibility can contribute a multiplicity or a manifold to cognition. But if so, then that seems to support the contention that Kant did not arrive at his mature conception of logic until the 1770s.

In the forgoing I have been stressing how Kant's faculty-oriented conception of logic's normativity is distinct from MacFarlane's characterization of logic as

\footnotetext{
${ }^{88}$ [MacFarlane, 2002, p. 49]. The other is "For a concept to have content is for it to be applicable to some possible object of sensible intuition."

${ }^{89}$ [MacFarlane, 2002, p. 49]
} 
merely studying the norms for thinking as such. Although I think I have presented good reasons for thinking they are distinct, at this point unsympathetic readers might press that MacFarlane's normativity just is supposed to be Kant's faculty-oriented normativity. Granting this for the moment will be instructive. This is because how we then construe this shared normativity will not be neutral between Kant's and Frege's positions. On the one hand, if we follow Kant in maintaining that any manifold or multiplicity in the objects of thought must stem from sensibility, then abstraction away from objects will be one component of this normativity. On the other hand, if we follow Frege in maintaining that there is no distinction to be drawn between the laws of thinking in general and

the laws of thinking of objects in general, then abstraction away from objects will seem to be extraneous to the conception of logic marked off by this normativity. So if we admit that MacFarlane's normativity for thinking as such just is Kant's faculty oriented-normativity are we at loggerheads? Would my position and MacFarlane's be equally defensible? No. Remember, what MacFarlane needed to establish was that there was some neutral shared conception of logic on which to adjudicate the dispute over logicism. And what this standoff would show is exactly that the purported neutral ground is not neutral. It can be construed in either a Kantian or Fregean way. And which way this construal goes will effect the prospects of reducing arithmetic to analytic judgments.

\section{Conclusion}

In this essay we have been examining MacFarlane's claim that Kant and Frege share the same fundamental conception of logic as 'the science of the rules governing thought as such.' We have seen that although Frege and Kant might agree on this nominal specification of logic, this agreement papers over a deeper disagreement about the senses in which each would take logic to be normative. 
Specifically, we have seen that Kant's characterization of what is essential to logic refers to the understanding, our faculty for thinking, while Frege's excludes such a reference to faculties. Further, Kant distinguishes two ways in which pure general logic is normative, as a canon and a propaedeutic, and neither of these can offer enough of a common conception of logic with Frege for a judicable dispute over the analyticity of arithmetic. Finally, we examined MacFarlane's arguments for why abstraction away from objects is a derivative feature of Kant's pure general logic, and saw that the same evidence could be marshaled in favor of viewing abstraction from objects as essential to Kant's logic. This was because Kant did not have his mature conception of the understanding (and thus pure general logic) until he realized that objects - a multiplicity or manifold of individuals - could not be given through it, but must be given through receptivity. Thus, if there is enough of a shared conception of logic for Kant and Frege to have a substantive judicable dispute over the plausibility of logicism, MacFarlane has not uncovered it.*

${ }^{\star}$ This essay has been a long time in the making. I first drafted it after a seminar from Thomas Ricketts on Frege around a decade ago, and it, as well as the larger project of which it is a part, were especially indebted in their nascent stages to conversations with him and Stephen Engstrom. Some of the thoughts in this essay appeared in a talk focused on the thought of note 78 which I first gave at a conference on logical form in the fall of 2012 at the University of Cambridge. I returned to this topic for a small workshop on Kant at Humboldt Universität, in the Summer of 2016 with Ralph Bader, Till Hoeppner, Andrew Stephenson, and Clinton Tolley and again that fall for a meeting of the Midwestern Study Group of the North American Kant Society. I then reworked the essay from scratch, at which point it became recognizably this essay. This I gave as a talk at the University of Belgrade, and a conference on the normativity of logic in Bergen in the summer of 2017, as well as at the winter of 2018 Eastern American Philosophical Association, and the Summer of 2018 Eastern Study Group of the North American Kant Society. I am indebted to many of the helpful comments and suggestions made on all of these occasions as well as the written comments and suggestions made by the editors and referees that worked to see this essay come in to print. Finally, I am grateful to Matthew Babb, Kathryn Lindeman, Colin McQuillan, Alexandra Newton, Thomas Pendlebury, Michael Sperberg-McQueen, and Shawn Standefer who all gave me comments on earlier versions. This essay has been in the works for long enough that I fear I've left someone out of this acknowledgement. If that is you, I apologize. 


\section{Note on Kant's texts}

In citing the Critique of Pure Reason I use the standard A and B edition numbering. For other works I use the standard "volume:page number" of the Academy edition of Kant's works, as well as the Kantian Review abbreviations for specific works, when available. Of course, we do not have a work on pure general logic that was authored and published by Kant, so we must rely on Kant's notes in the logic textbook he lectured from (Meier's Auszug Aus der Vernunftlehre), notes taken by Kant's students during his logic lectures, and the logic text prepared by Kant's student Jäsche (at Kant's request) for Kant's views on the subject. I have generally tried to corroborate claims from the logical works with multiple sources. 


\section{References}

Lanier Anderson. It adds up after all: Kant's philosophy of arithmetic in light of the traditional logic. Philosophy and Phenomenological Research, 69(3): 501-540, 2004.

Lanier Anderson. Neo-kantianism and the roots of anti-psychologism. British Journal for the History of Philosophy, 13(2):287-323, 2005.

Lanier Anderson. The Poverty of Conceptual Truth: Kant's Analytic/Synthetic Distinction and the Limits of Metaphysics. Oxford University Press, first edition, 2015.

Michael Beaney. Frege and the role of historical elucidation: Methodology and the foundations of mathematics. In Jeremy Gray José Ferreirós, editor, the Architecture of Modern Mathematics, pages 47-66. Oxford University Press, 2006.

Matthew Boyle. Kant on logic and the laws of the understanding. In Sofia Miguens, editor, The Logical Alien: Conant and his critics. Harvard University Press, 2020.

Angela Breitenbach. Die Analogie von Vernunft und Natur: eine Umweltphilosophie nach Kant, volume 159 of Kantstudien. Ergänzungshefte. Walter de Gruyter, Berlin, 2009.

Jill Vance Buroker. Kant's Critique of pure reason: an introduction. Cambridge University Press, Cambridge, 2006.

Alberto Coffa. The Semantic Tradition From Kant to Carnap: To the Vienna Station. Cambridge University Press, 1991.

James Conant. The search for logically alien thought: Descartes, Kant, Frege, and the Tractatus. Philosophical topics, 20(1):115-180, 1992. 
James Conant. The logical alien revisited: Afterthoughts and responses. In Sofia Miguens, editor, The Logical Alien: Conant and his critics. Harvard University Press, 2020.

Robert Cummins. Functional analysis. The Journal of Philosophy, 72(20):741$765,1975$.

Gottlob Frege. The Foundations of Arithmetic: A Logico-Mathematical Enquiry Into the Concept of Number. Northwestern University Press. 1980, 1884.

Gottlob Frege. Grundgesetze der Arithmetik: I-II Band, volume 1. H. Pohle, 1893.

Gottlob Frege. Thought. In Michael Beaney, editor, The Frege Reader. Basil Blackwell. 1997, 1918.

Warren Goldfarb. Frege's conception of logic. In Juliet Floyd and Sanford Shieh, editors, Future pasts: The analytic tradition in twentieth-century philosophy, pages 25-41. Oxford University Press, New York, 2001.

Thomas Hofweber. Logic and ontology. In Edward N. Zalta, editor, The Stanford Encyclopedia of Philosophy. Metaphysics Research Lab, Stanford University, winter 2017 edition, 2017.

Immanuel Kant. Gesammelte Schriften. 29 vols. Walter de Gruyter, GmbH, Berlin, 1979.

Immanuel Kant. Critique of Pure Reason. The Cambridge Edition of the Works of Immanuel Kant in Translation. Cambridge University Press, Cambridge, 1999.

Immanuel Kant. Lectures on Logic. The Cambridge Edition of the Works of Immanuel Kant in Translation. Cambridge University Press, Cambridge, 2004. 
Erich Reck \& Pierre Keller. From Dedekind to Cassirer: Logicism and the kantian heritage. In Ofra Rechter \& Carl Posy, editor, Kant's Philosophy of Mathematics, Vol. II. Oxford University Press, Forthcoming.

Michael Kremer. Logicist responses to Kant: (early) Frege and (early) Russell. Philosophical Topics, 34(1/2):163-188, 2006.

Jessica Leech. The normativity of Kant's logical laws. History of Philosophy Quarterly, 42017.

Øystein Linnebo. Frege's conception of logic: From Kant to Grundgesetze. Manuscrito, 26(2):235-252, 2003.

Béatrice Longuenesse. Kant on the Human Standpoint. Modern European Philosophy. Cambridge University Press, 2005.

Huaping Lu-Adler. Kant on the logical form of singular judgements. Kantian Review, 19(3):367-392, 2014.

Huaping Lu-Adler. Kant and the normativity of logic. European Journal of Philosophy, 25:207-230, 2016.

John MacFarlane. Frege, Kant, and the logic in logicism. Philosophical Review, 111(1):25-65, 2002.

Penelope Maddy. Second Philosophy: A Naturalistic Method. Oxford University Press, 2007.

Melissa McBay Merritt. Varieties of reflection in Kant's logic. British Journal for the History of Philosophy, 23(3):478-501, 2015.

Ruth Garrett Millikan. In defense of proper functions. Philosophy of Science, $56(2): 288-302,1989$. 
Alexandra Newton. Kant on negation. Australasian Journal of Philosophy, 0 (0):1-20, 2020.

Tyke Nunez. Logical mistakes, logical aliens, and the laws of Kant's pure general logic. Mind, 128(512):1149-1180, October 2019.

Tyke Nunez. Review of Huaping Lu-Adler. Kant and the Science of Logic: A Historical and Philosophical Reconstruction. Journal for the History of Analytical Philosophy, 8(7):16-31, 2020.

Tyke Nunez. Kant on Vitalism and the analogy with life. In Camilla SerckHanssen and Beatrix Himmelmann, editors, Proceedings of the 13th International Kant Congress 'The Court of Reason' (Oslo, 6-9 August 2019). Walter de Gruyter, Forthcoming.

Tyke Nunez. The formality of Kant's logic and consciousness of logical laws. manuscript.

Henri Poincaré. Science and Method. With a Preface by the Honorable Bertrand Russell. Thomas Nelson \& Sons, London, 1914.

Hilary Putnam. Rethinking mathematical necessity. In James Conant, editor, Words and Life, pages 245-264. Harvard University Press, 1994.

Erich H. Reck. Frege, Dedekind, and the origins of logicism. History and Philosophy of Logic, 34(3):242-265, 2013.

Thomas Ricketts. Frege, the Tractatus, and the logocentric predicament. Noûs, 19(1):3-15, 1985.

Jay F Rosenberg. Accessing Kant: a Relaxed Introduction to the Critique of Pure Reason. Oxford University Press, 2005. 
Bertrand Russell. Principles of Mathematics. W.W. Norton and Company, New York, 1938.

Sanford Shieh. Necessity lost: Modality and Logic in Early Analytic Philosophy, Vol 1. Oxford University Press, first edition edition, 2019.

Hans Sluga. Gottlob Frege. Routledge, 1980.

Florian Steinberger. The normative status of logic. In The Stanford encyclopedia of philosophy. 2017.

William Taschek. Truth, assertion, and the horizontal: Frege on the essence of logic. Mind, 117(466):375-401, 2008.

Mark Textor. Frege on judging as acknowledging the truth. Mind, 119(475): 615-655, 10 2010a.

Mark Textor. Routledge Philosophy Guidebook to Frege on Sense and Reference. Routledge, 2010b.

Clinton Tolley. Kant on the nature of logical laws. Philosophical Topics, 34 (1/2):371-407, 2006.

Clinton Tolley. The generality of Kant's transcendental logic. Journal of the History of Philosophy, 50(3):417-446, 2012.

Clinton Tolley. Kant on the generality of logic. In Margit Ruffing, Claudio La Rocca, Alfredo Ferrarin, and Stefano Bacin, editors, Proceedings of the 11th International Kant Congress. Vol. 2, pages 431-442. De Gruyter, 2013.

Maria van der Schaar. Frege on judgement and the judging agent. Mind, 127 (505):225-250, 052018 .

Hao Wang. A Survey of Mathematical Logic. Science Press, Peking, 1963. 
Wayne Waxman. Kant's Anatomy of the Intelligent Mind. Oxford University Press, 2013.

Michael Wolff. Die Vollständigkeit der Kantischen Urteilstafel Mit Einem Essay Über Freges Begriffsschrift. Vittorio Klostermann, Frankfurt am Main, 1995.

Michael Wolff. Die reinheit der reinen logik: Kant und Frege. In Jürgen Stolzenberg, editor, Kant in der Gegenwart, pages 53-70. Walter de Gruyter, 2007. 